\title{
Literature Review: Masalah Kesehatan Anak Jalanan
}

\section{Literature Review: The Health Problem of Street Children}

\author{
Akmal Haekal Az Zam Zami ${ }^{1}$, Elsye Maria Rosa ${ }^{2}$ \\ ${ }^{1}$ Mahasiswa magister Keperawatan, Universitas Muhammadiyah Yogyakarta, Indonesia \\ ${ }^{2}$ Dosen Magister Keperawatan Universitas Muhammadiyah Yogyakarta
}

\section{ARTICLE INFO}

\section{Article history}

Received date

19 May 2021

Revised date

27 May 2021

28 Jun 2021

Accepted date

08 Sept 2021

\section{Keywords:}

Problem health;

Risk factors;

Street children.

\section{Kata kunci:}

Masalah kesehatan;

Faktor resiko;

Anak jalanan.

\author{
ABSTRACT/ ABSTRAK
}

An increase in the number of street children saved by the world due to several factors such as family problems, poverty, difficulties in the household, parents, challenges, and family assistance are also reasons why children prefer to choose the road. This literature review aims to analyze or find out about health problems in street children. After reviewing the 5 articles, it can be concluded that three problems are often faced by street children, namely physical, psychological and social health problems. The problem of street children is a shared responsibility, the need for the role of cross-sectoral cooperation, both government, community, and educational institutions to solve the problems of street children. From this research, it is concluded that three problems are often faced by street children, namely physical, psychological and social health problems. Physical problems often experienced by street children are growth and nutrition problems, physical injuries, parasites and community-acquired infectious diseases, sexual and reproductive health problems, sexual violence and abuse, drug use and abuse. Meanwhile, the psychological problems of street children include psychiatric disorders such as depression, hopelessness, and suicidal thoughts. The social health problems of street children are economic and social. Street children are also often victims of neglect, psychological, physical, sexual abuse and are susceptible to sexually transmitted infections.

\begin{abstract}
Terjadinya peningkatan jumlah anak jalanan diseluruh dunia disebabkan oleh beberapa faktor diantaranya adalah masalah keluarga, kemiskinan, kekerasan dalam rumah tangga, kehilangan orang tua, kurangnya perlindungan serta dukungan keluraga juga menjadi alasan kenapa seorang anak lebih memilih hidup dijalan. Literature review ini bertujuan untuk menganalisis atau mengetahui tentang masalah kesehatan pada anak jalanan. Setelah melakukan telaah terhadap 5 artikel dapat diambil kesimpulan bahwa terdapat tiga permasalahan yang sering dihadapi anak jalanan yaitu masalah kesehatan fisik, psikologi dan sosial. Permasalahan anak jalanan menjadi tanggung jawab bersama, Perlunya peran kerja sama lintas sektor baik pemerintah, masyarakat, dan institusi pendidikan untuk menyelesaikan permasalahan anak jalanan. penelitian ini diambil kesimpulan bahwa terdapat tiga permasalahan yang sering dihadapi anak jalanan yaitu masalah kesehatan fisik, psikologi dan sosial. Permasalahan fisik yang sering dialami anak jalanan berupa gangguan pertumbuhan dan gizi, cedera fisik, parasit dan penyakit menular yang didapat masyarakat, gangguan kesehatan reproduksi dan seksual, kekerasan dan pelecehan seksual, penggunaan dan penyalahgunaan narkoba. Sedangkan permasalahan psikologis anak jalanan meliputi gangguan kejiwaan seperti depresi, keputusasaan, dan keinginan bunuh diri. Permasalan kesehatan sosial anak jalanan yaitu masalah ekonomi dan sosial. Anak jalanan juga sering kali menjadi korban penelantaran, pelecehan psikologis, fisik, seksual dan rentan terkena penyakit infeksi seksual menular (HIV).
\end{abstract}

\section{PENDAHULUAN}

Anak-anak merupakan aset sebuah bangsa. Hak-hak dan kebutuhan anak telah menjadi kesadaran dunia international. Kehadiran anak jalanan merupakan sebuah manifestasi dari kelalaian dunia international. UNICEF memperkirakan terdapat jutaan anak-anak tinggal 
dan bekerja di jalanan dan jumlah ini terus mengalami peningkatan. UNICEF (2019) menyebutkan terdapat hampir 150 juta anak jalanan yang tinggal didaerah perkotaan maupun semi perkotaan. Menurut United Nations Children's Fund (UNICEF) kategori anak jalanan dibagi menjadi tiga kelompok, yaitu : Children of the street, yaitu anak-anak yang meninggalkan rumah dan memutuskan untuk tidak berhubungan dengan keluarganya lagi. Mereka biasanya tidak memiliki tempat tinggal dan pekerjaan yang tetap, sehingga mereka tinggal, tidur dan memenuhi kebutuhan dasar di jalan-jalan perkotaan maupun semi perkotaan. Children on the street, yang disebut juga sebagai pekerja anak dijalan. Mereka menghabiskan sebagian besar waktu mereka untuk bekerja di jalanan atau tempat-tempat umum untuk membantu ekonomi keluarganya tetapi pada malam hari mereka kembali kerumah untuk istirahat. Children in the street, yaitu anak-anak yang hidup dan tinggal bersama keluarganya di jalanan.

Populasi anak jalanan yang dilaporkan dalam studi terdiri dari laki-laki dan perempuan. Sejumlah penelitian dari Afrika Selatan dan Utara (Mesir) menunjukkan sebagian besar anak jalanan adalah laki - laki. Sementara beberapa bagian Afrika Timur dan Barat anak jalanan terdiri dari sejumlah kecil gadis (kurang dari 30\%). Anak-anak tersebut biasanya berusia antara 12 dan 17 tahun, meskipun beberapa penelitian di Afrika Barat mengidentifikasi anakanak jalanan berusia sekitar 7 tahun. Penelitian menunjukkan bahwa beberapa anak jalanan memiliki sedikit atau tidak ada kontak dengan keluarga mereka dan kebanyakan dari mereka tinggal di bagian kota yang berbahaya seperti di bawah jembatan, di dalam dan di sekitar pasar kota dan tempat-tempat gelap lainnya (Attia, et al., 2017).

Terjadinya peningkatan jumlah anak jalanan diseluruh dunia disebabkan oleh beberapa hal dantaranya masalah keluarga, kemiskinan, kekerasan dalam rumah tangga, kehilangan orang tua, kurangnya perlindungan serta dukungan keluraga juga menjadi alasan kenapa seorang anak lebih memilih hidup dijalan (Attia, et al., 2017). Pendapat lain menyatakan bahwa penyebab adanya anak jalanan yaitu keadaan politik, kemiskinan, trauma dimasa kecil (Cénat, et al., 2018). Penyebab seorang anak lebih memilih hidup dan bekerja dijalan umumnya berbeda disetiap negara tergantung pada situasi ekonomi, sosial dan politik. Bagi sebagian besar anak-anak di Brasil, Amerika Serikat, Jepang, dan Meksiko globalisasi adalah motif dasar untuk meninggalkan rumah mereka, sedangkan, di sebagian besar negara Afrika dan beberapa negara Asia (Sudan, Ethiopia, Madagaskar, Kenya, India, Pakistan), kemiskinan, kematian orang tua, tekanan teman sebaya, tekanan keluarga adalah kekuatan pendorong utama untuk menjadi anak jalanan (Alem \& Laha, 2019). Putus sekolah dasar juga menjadi salah satu karakteristik umum di antara para anak jalanan (lebih dari 70\% melakukannya), meskipun beberapa tidak pernah bersekolah sama sekali. Alasan terakhir adalah keluarga tidak mampu membayar biaya sekolah dan sebagian besar anak berasal dari keluarga poligami dan besar dengan rata-rata 4 hingga 9 anak per rumah tangga. Sebagian besar penelitian di selatan dan Afrika Barat melaporkan bahwa pengalaman anak perempuan jalanan lebih parah daripada anak laki-laki. Di sisi lain, gadis jalanan ditemukan lebih setuju daripada anak jalanan untuk direkrut ke institusi, tinggal dengan kerabat, direkrut menjadi pekerja seks, ditipu untuk jatuh dalam hubungan dengan sugar dady laki-laki yang lebih tua, membuat mereka kurang terlihat di jalanan daripada anak laki-laki

Anak-anak jalanan rentan menjadi korban penyalahgunaan segala bentuk, kekerasan, eksploitasi, dan perlakuan tidak manusiawi oleh antisosial dan penjahat (Deb, et al., 2020). Selain itu, Banyak sekali tantangan yang harus dihadapi anak jalanan setiap harinya. Tantangan tersebut meliputi tidak adanya tempat tinggal, pakaian dan makanan yang layak, tidak dapat menerima akses pendidikan dan perawatan kesehatan, penyakit fisik kronis seperti penyakit gastrointestinal, IMS dan gangguan fisik lainnya (Diallo, et al., 2015). Selain itu anak jalanan beresiko mengalami gangguan psikologis, sifat kepribadian maladaptif, alkohol dan kecanduan obat psikoaktif dan masih banyak lainya.

PBB telah memiliki kebijkaan dalam melindungi anak anak di dunia, UNICEF sendiri memiliki misi yang diberikan oleh Majelis Umum PBB untuk advokasi perlindungnan hak anak-anak, untuk turut memberikan keperluan dasar mereka, memperluas peluang anak untuk menggapai potensi yang mereka iliki (UNICEF, 2019) Pemerintah Indonesia sebenarnya sudah menetapkan regulasi terkait upaya perlindungan anak, tentunya termasuk anak jalanan. Pada Undang Undang Perlindungan Anak Nomor 23 Tahun 2002 dinyatakan bahwa perlindungan anak adalah segala kegiatan untuk menjamin dan melindungi anak dan hak-haknya agar dapat hidup, tumbuh, berkembang, dan berpartisipasi, secara optimal sesuai dengan harkat dan martabat kemanusiaan, serta mendapat perlindungan dari 
kekerasan dan diskriminasi (Nuzula, 2019)

Fenomena merebaknya anak jalanan di Indonesia merupakan problem sosial yang sangat kompleks (Zaman, 2019). Menurut UUD 1945, "anak terlantar itu dipelihara oleh negara" yang bermakna pemerintah mempunyai tanggung jawab terhadap pemeliharaan dan pembinaan anak-anak terlantar, termasuk anak jalanan. Hakhak asasi anak terlantar dan anak jalanan, pada hakekatnya sama dengan hak-hak asasi manusia pada umumnya. Mereka perlu mendapatkan hakhaknya secara normal sebagaimana layaknya anak, yaitu hak sipil dan kemerdekaan (civil rights and freedoms), lingkungan keluarga dan pilihan pemeliharaan (family envionment and alternative care), kesehatan dasar dan kesejahteraan (basic health and welfare), pendidikan, rekreasi dan budaya (education, laisure and culture activites), dan perlindungan khusus (special protection).

Keberadaan anak jalanan berhubungan langsung dengan tidak terpenuhinya kebutuhan dasar anak yang meliputi kebutuhan fisik, psikologis, sosial dan spiritual sehingga mereka tidak mampu menjalankan fungsi sosialnya sebagai anak secara alami. Untuk itu, anak-anak berusaha untuk menemukan pemenuhan kebutuhan ini dengan turun ke jalan (Zulfendri, et al., 2017). Berdasarkan situasi diatas, maka perlu digali lebih lanjut bagaimana mengenai permasalahan dasar anak jalanan.

Metode yang digunakan dalam tulisan literature review ini menggunakan systematic review dengan PRISMA (Preferred Reporting Items for systematic review and Meta-analyses). Pada prinsipnya systematic review ini merupakan metode penelitian yang dilakukan dengan merangkum hasil artikel penelitian primer sebagai tujuan untuk menyajikan data lebih komprehensif dan berimbang. Literature review ini dilakukan dengan menggunakan 4 (empat) tahapan, yaitu:

1. Menentukan kriteria kelayakan

Kriteria kelayakan literature dilakukan dengan menentukan kriteria inklusi, yaitu: dimana artikel yang ditelaah merupakan hasil riset asli yang telah dikaji dan dipublikasikan dalam bahasa inggris, serta tujuan artikel yang ditinjau harus memuat data mengenai pemenuhan kebutuhan dasar anak jalanan.

2. Menentukan sumber informasi

Pencarian literatur dilakukan dengan menggunakan 2 (dua) data base online yaitu: Google Scholar dan PubMed.

3. Pemilihan literatur

Kriteria dalam pemilihan literature review ini dilakukan dengan menentukan kata kunci berupa kunci "Needs Fulfillment AND Street Children". Limitasi yang dilakukan untuk pencarian artikel yang terkait dengan pemenuhan kebutuhan dasar anak jalanan yaitu 5 tahun terakhir diantara tahun 2015 sampai dengan tahun 2019.

4. Pengumpulan data

Pengumpulan data literature review ini dilakukan secara manual dengan cara memfilter data sesuai dengan kriteria inklusi dan pencarian menggunakan kata kunci "Needs Fulfillment and Street Children" yang digunakan. Pencarian artikel menggunakan database Pubmed dan Google Scholar hasil pencarian didapatkan Pubmed 20 artikel sedangkan Google Scholar 233.036 artikel. Kemudian artikel yang relevan dengan literature review ini sebanyak 5 artikel.

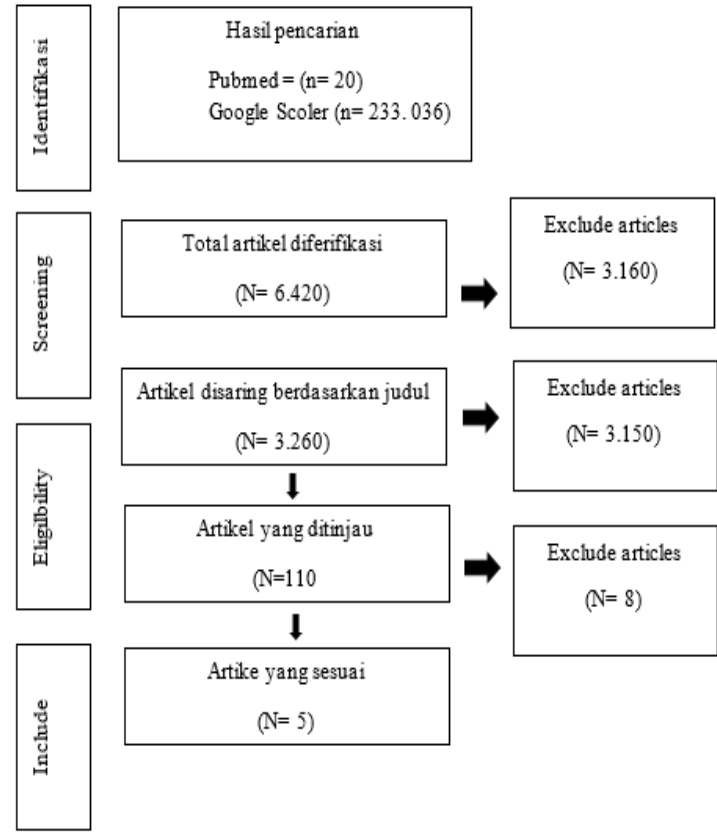

Gambar 1. Tahapan Pemilihan Artikel

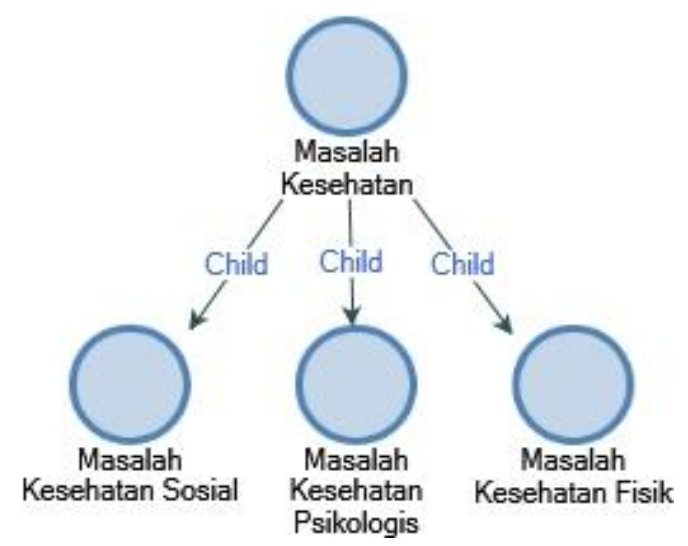

Gambar 2. Masalah Kesehatan Anak Jalanan 
Tabel 1. Cluster Analisis masalah kesehatan anak jalanan

\begin{tabular}{llr}
\hline \multicolumn{1}{c}{ Cluster A } & Cluster B & \multicolumn{1}{c}{$\begin{array}{c}\text { Pearson } \\
\text { correlation } \\
\text { coefficient }\end{array}$} \\
\hline $\begin{array}{l}\text { Masalah Kesehatan } \\
\text { Fisik }\end{array}$ & $\begin{array}{l}\text { Masalah } \\
\text { Kesehatan } \\
\text { Masalah Kesehatan }\end{array}$ & $\begin{array}{l}\text { Masalah } \\
\text { Psikologis }\end{array}$ \\
$\begin{array}{l}\text { Kasalah Kesehatan } \\
\text { Sosial }\end{array}$ & $\begin{array}{l}\text { Masalah } \\
\text { Kesehatan }\end{array}$ & 0,47 \\
\hline
\end{tabular}

Dalam masalah kesehatan anak jalanan, masalah kesehatan fisik sangat erat kaitanya dengan masalah kesehatan dengan nilai korelasi 0,75. Di ikuti oleh factor kesehatan psikologis dengan masalah kesehatan $(0,47)$ dan masalah kesehatan sosial dengan masalah kesehatan $(0,43)$

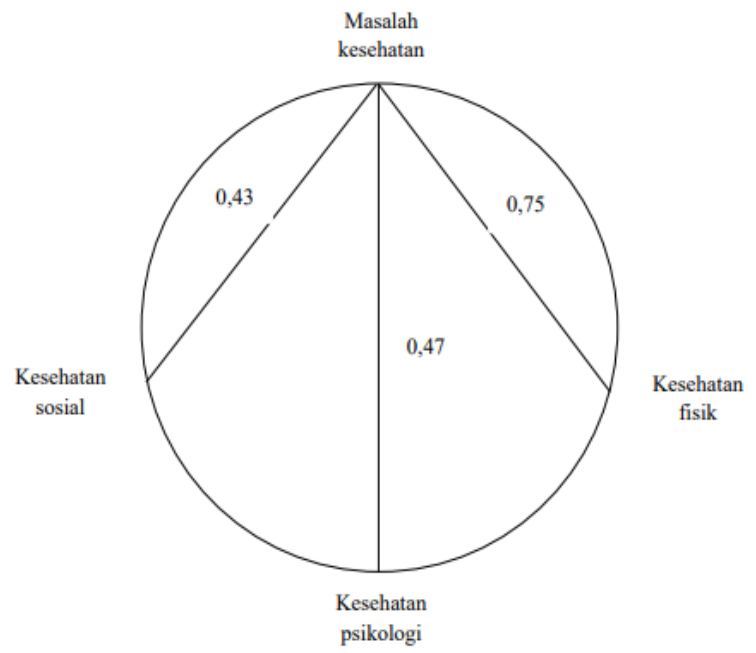

\section{Gambar 3. Cluster Diagram Analisis Masalah} Kesehatan Anak Jalanan

Fokus utama dari literature review ini adalah untuk mengetahui tentang masalah kesehatan pada anak jalanan. Hasil telaah dari 5 artikel didapatkan temuan sebagai berikut:

a. Masalah kesehatan fisik (Ayub, et al., 2016; Bhusal, 2016; Zulfendri, et al., 2017)

b. Masalah kesehatan psikologis (Cénat, et al., 2018; Zulfendri, et al., 2017)

c. Masalah kesehatan sosial (Ramu, 2018; Zulfendri, et al., 2017)

\section{PEMBAHASAN}

\section{Masalah Kesehatan Fisik}

Anak jalanan adalah seorang anak yang berusia 6-15 tahun yang tidak bersekolah dan tidak tinggal bersama orang tua, mereka bekerja dan bertahanan hidup dijalan (Nayak, 2018). Dalam beberapa penelitian seperti yang di sebutkan dalam penelitian (Tefera, 2015) disebutkan bahwa anak jalanan mempunyai banyak masalah diantaranya masalah kesehatan fisik. Kesehatan fisik merupakan kesejahteraan tubuh dan berfungsinya organisme individu. Kesehatan fisik seringkali dipahami sebagai tubuh manusia yang bebas dari penyakit atau kecacatan.

The United Nations Children's Fund telah memberi label anak-anak jalanan sebagai populasi minoritas yang terlalu lama kurang terwakili dalam penelitian kesehatan. Hal ini memprihatinkan karena anak jalanan berisiko menanggung beban penyakit yang lebih berat. Gaya hidup anak jalanan membuat mereka lebih rentan terhadap risiko dan masalah kesehatan daripada anak-anak yang tinggal di rumah; saat mereka berkeliaran di jalan-jalan meminta makanan dan uang untuk memenuhi kebutuhan dasar dan ditemukan tidur di rumahrumah yang setengah hancur, ruang bawah tanah yang ditinggalkan, di bawah jembatan dan di udara terbuka.

Gaya hidup anak jalanan yang tidak terkontrol membuat mereka lebih rentan terhadap resiko dan masalah kesehatan dibandingkan anak-anak yang tinggal dirumah. Masalah kesehatan yang paling sering ditemukan adalah gangguan pertumbuhan dan gizi, cedera fisik, parasit dan penyakit menular yang didapat masyarakat, gangguan kesehatan reproduksi dan seksual, kekerasan dan pelecehan seksual, penggunaan dan penyalahgunaan narkoba, kesehatan mental masalah akses ke layanan perawatan kesehatan dan praktik seks transaksional dan konsekuensinya (Cumber \& Tsoka-Gwegweni, 2015). Penelitian oleh (Zulfendri, et al., 2017) menjelaskan bahwa masalah kesehatan fisik yang sering diderita oleh anak jalanan adalah demam, influenza, bisul, kudis, iritasi kulit,batuk dan masalah pernapasan anak jalanan memiliki sedikit atau bahkan sama sekali tidak memiliki akses ke perawatan kesehatan untuk mengatasi masalah fisik yang mereka hadapi. Tingginya biaya rawat inap dan konsultasi dengan dokter ahli merupakan penghalang utama bagi anak jalanan yang berpenghasilan rendah atau tidak sama sekali(Cumber \& Tsoka-Gwegweni, 2015). Hambatan lain yang muncul adalah stigma negative dari penyedia layanan kesehatan, status minoritas dan tidak yakin terhadap kualitas pelayanan dari pusat kesehatan yang akan mereka terima karena status mereka yang kurang beruntung. Selain itu anak jalanan mengaku tidak 
mempunyai waktu untuk datang kepusat layanan keehatan pada siang hari karena berjuang mengumpulkan uang untuk membeli makanan dan memenuhi kebutuhan dasar lainya (Fiasorgbor \& Fiasorgbor, 2015).

adanya pengaruh yang diberikan oleh keluarga sejak kecil tentang bagaimana kehidupan di jalanan secara tidak langsung menjerumuskan anak untuk berada di jalanan. Seperti salah satu informan anak jalanan yang sudah berada di jalanan sejak lahir bersama ibunya. Keadaan ekonomi lah yang membuat keluarga terpaksa menjerumuskan anak untuk ikut bekerja di jalanan. Pemenuhan kebutuhan hidup yang tidak dapat terpenuhi mengharuskan anak untuk membantu orangtua dalam mencari penghasilan (Tumangger \& Riasih, 2020)

Pemerintah Indonesia mempunyai peraturan tentang kesehatan bagi warga negara yang tertuang dalam UU No.36 tahun 2009 tentang kesehatan di Indonesia pasal 11 dinyatakan bahwa setiap orang berkewajiban berperilaku dengan cara yang sehat untuk menyadai, memelihara, dan mempromosikan kesehatan setinggi mungkin. Peraturan tersebut berlaku juga bagi anak jalanan. Peran dari institusi kesehatan diperlukan untuk mencegah dan mengobati berbagai masalah kesehatan yang dihadapi oleh anak jalanan karena bagaimanapun juga anak jalanan merupakan tanggung jawab negara (Van Daalen, et al., 2016).

\section{Masalah Kesehatan Psikologi}

Anak jalanan seringkali didefinisikan sebagai remaja yang tidak memiliki tempat tinggal permanen. Remaja yang menjadi anak jalanan dibentuk oleh berbagai faktor yang mempengaruhi kehidupan mereka, termasuk latar belakang keluarga, kesehatan mental dan situasi kehidupan. Faktor yang sangat kompleks tersebut menjadi pendorong seorang anak lebih memilih turun dijalan.

Keterlibatan anak-anak untuk bekerja dipengaruhi oleh adanya faktor kemiskinan. Bagi keluarga miskin sekecil apapun penghasilan anak-anak yang bekerja ternyata mampu menyokong kelangsungan hidup keluarga. Artinya kontribusi ekonomi yang diberikan oleh anak dianggap penting bagi penghasilan orangtua dan akan terjadi penurunan pendapatan orangtua apabila anak-anak mereka berhenti bekerja. Jelas bahwa kemiskinan merupakan persoalan yang paling buruk dan kronis bagi manusia dalam kehidupan masyarakat yang kini semakin bertambah kompleks. Ketidak mampuan orangtua memenuhi kebutuhanhidup sehari-hari memaksa mereka mempekerjakan anaknya untuk membantu mencukupi kebutuhan ekonomi keluarga (Rakhmaniyah, 2020).

Hal ini dikarenakan jika pendidikan anak ja lanan rendah, maka ketrampilan, keahlian dan pengalaman anak jalanan dalam bekerja pun kurang untuk melamar pekerjaan dengan penghasilan yang cukup tinggi, dan biasanya ditempat kerja dibutuhkan durasi waktu tertentu dan berbagai aturan yang harus ditaati sehingga mereka merasa tidak bebas dalam melakukan halhal yang ia sukai. Jika turun dijalan mereka mendapatkan uang tanpa memerlukan keahlian khusus, tanpa peraturan yang membuat mereka terbebani dan tanpa terbatas oleh waktu. (Mugianti, et al., 2018)

Selain itu mereka juga beranggapan bahwa keluarga juga kurang bias memenuhi kebutuhan yang mereka perlukan misalnya kebutuhan sandang, pangan, uang jajan, serta modal untuk tampil berpakaian yang menggambarkan jati diri mereka sendiri, sehingga demi memenuhi kebutuhan mereka sehari-hari meraka memutuskan untuk mengamen agar mendapat uang. Sebagian besar remaja yang menjadi anak jalanan juga beranggapan apabila mereka mencari uang sendiri mereka akan dianggap sebagai orang yang mandiri dan menjadi anak jalanan merupakan pilihan terakhiryang mereka pilih (Suryaningsih \& Nur, 2020)

Anak jalanan mengalami banyak sekali mengalami trauma yang bersifat kompleks. Peristiwa kehidupan yang sulit, trauma interpersonal maupun non-interpersonal yang berlipat ganda, pengabaian, kondisi hidup yang susah, penganiayaan, psikologis, fisik (pemukulan dan cedera berulang dan berulang), seksual (termasuk pemerkosaan dan pedofilia), komunitas dan sosial (paparan mayat, diskriminasi sosial), kekerasan politik, dan bencana alam adalah trauma yang dialami anakanak jalanan (Haydar, 2017). Sedangkan menurut (Zulfendri, et al., 2017) anak jalanan yang mengalami beberapa trauma cenderung mengalami penyakit mental diantaranya depesi, putus asa dan bunuh diri, akan tetapi beberapa anak jalanan mampu menunjukkan self efficacy untuk menghadapi pengalaman traumatis yang mereka alami. Menurut logika survival pengalaman sulit yang dialami oleh anak jalanan mampu menjadi bekal dalam menghadapi masalah yang akan datang. Anak jalanan memilik tingkat dukungan sosial yang rendah, dalam jurnal penelitian (Cénat, et al., 2018) adanya hubungan yang signifikan antara kebutuhan 
dukungan sosial dan kebutuhan dasar anak jalanan.

\section{Masalah Kesehatan Sosial}

Anak jalanan termasuk anggota masyarakat yang paling rentan dan terpinggirkan, seringkali tidak memiliki akses ke makanan, tempat tinggal, perawatan kesehatan, keamanan dan pendidikan. Banyak anak jalanan makan dari tempat sampah, tidur dengan pakaian minim, dan dianiaya oleh orang lain. Situasi ini dapat mengakibatkan disosiasi yang memungkinkan seorang anak untuk hampir menghilangkan dirinya dari situasi tersebut, membuatnya mati rasa dari kenyataan, dan mencapai pemisahan antara tubuh dan pikiran pada saat itu sebagai mekanisme perlindungan

Kehidupan di jalanan selalu menjadi sebuah tantangan untuk bertahan hidup tidak hanya bagi orang dewasa tetapi juga anak-anak. Studi yang dilakukan diantara anak jalanan telah menunjukan bahwa selain masalah ekonomi dan sosial mereka juga sering kali menjadi korban penelantaran, pelecehan psikologis, fisik, seksual dan rentan terkena penyakit infeksi seksual menular (HIV) (RamBihariLal Shrivastava, 2014). Selain berbagai masalah tersebut, kehidupan anak jalanan juga menyebabkan mereka rentan menghadapi trauma. Trauma yang dialami anak jalanan akan mempengaruhi perkembangan psikososial dan akan menyebabkan stress. semakin tinggi tingkat stress anak jalanan akan menyebabkan berbagai masalah perilaku antisosial (Oppong Asante, 2016).

Anak jalanan sering kali mendapatkan kekerasan psikologis berupa tindakan pencemoohan, seperti kata-kata kasar dan menyindir yang berasal dari supir angkutan umum dan penumpangnya. Hal tersebut merupakan sumber stres bagi anak-anak. Mereka akan merasa tidak dihargai dan diharapkan untuk berada di tengah-tengah masyarakat (Wardani, 2018)

Hasil dari penelitian (Ramu, 2018) menunjukkan perilaku anti sosial yang ditunjukan anak jalanan yaitu memukul, mengumpat, cengeng, tidak jujur dan tidak bisa sabar. Faktor yang mendorong perilaku antisosial tersebut adalah pola asuh yang salah, kurangnya akses pendidikan dan perilaku antisosial di lingkungan masyarakat tempat tinggal anak baik teman bermain maupun orang dewasa yang mereka lihat sehari-hari.

Pendidikan merupakan kebutuhan dasar untuk anak-anak. Dalam berbagai tinjauan literatur menyatakan bahwa anak jalanan sering kali mengalami putus sekolah. Pendidikan yang pada dasarnya dapat mengubah seseorang dalam berpikir dan berperilaku lebih baik. Akan tetapi mereka tidak bisa menikmati fasilitas dari negara mereka (Cénat, et al., 2018). Kondisi ini terjadi karena rendahnya pemahaman orang tua dan masyarakat tentang tanggung jawab mereka kepada anak-anak dalam hal pendidikan. Pemenuhan pendidikan untuk warga negara telah diatur dalam pasal 9 ayat (1) undang-undang nomor 23 tahun 2002 tentang perlindungan anak dijelaskan "setiap anak berhak memperoleh pendidikan dan pengajaran dalam rangka pengembangan pribadinya dan tingkat kecerdasannya sesuai dengan minat dan bakat termasuk anak jalanan. Fasilitas yang disediakan pemerintah Indonesia untuk anak jalanan yang ingin melanjutkan sekolah dapat mengikuti pendidikan kejar paket A, B, dan C (Arini \& Pudjiati, 2017). Dalam mengatasi fenomena sosial terhadap anak jalanan sebenarnya perlu melibatkan peran litas sektor dan lintas program, dan yang paling penting adalah peran masyarakat. Penelitian yang dilakukan oleh (Hanafi, 2017) dalam amandemen UU No. 23 tahun 2002 tentang pengembangan dan perlindungan anak-anak peran masyarakat, baik melalui lembaga perlindungan anak, lembaga agama dan organisasi non pemerintah dan institusi pendidikan.

Banyaknya anak jalanan yang tidak bisa mendapatkan pendidikan formal di sekolah cenderung disebabkan oleh praktik diskriminasi yang dilakukan pihak sekolah terhadap mereka. Banyak alasan yang dikemukakan sekolah untuk menolak keberadaan anak jalanan menempuh pendidikan di sekolahnya. Umumnya sekolah formal tidak mau menerima anak-anak jalanan karena dianggap sebagai "biang" masalah, bahkan sikap dan perbuatan mereka dinilai sekolah dapat memengaruhi siswa lainnya. Namun demikian, seharusnya ini tidak berlaku untuk semua anak jalanan. Pada kasus-kasus tertentu ada anak-anak jalanan yang berpotensi dan berprestasi seperti anak-anak lainnya. Ini yang belum diakomodir oleh pemerintah sebagai bentuk penghapusan diskriminasi anak jalanan dalam dunia pendidikan (Astri, 2018).

\section{SIMPULAN}

Tulisan ini telah menyajikan beberapa tinjauan hasil penelitian yang berkaitan dengan masalah kesehatan anak jalanan. Setelah melakukan telaah terhadap 5 artikel dapat diambil kesimpulan bahwa terdapat tiga 
permasalahan yang sering dihadapi anak jalanan yaitu masalah kesehatan fisik, psikologi dan sosial. Permasalahan fisik yang sering dialami anak jalanan berupa gangguan pertumbuhan dan gizi, cedera fisik, parasit dan penyakit menular yang didapat masyarakat, gangguan kesehatan reproduksi dan seksual, kekerasan dan pelecehan seksual, penggunaan dan penyalahgunaan narkoba. Sedangkan permasalahan psikologis anak jalanan meliputi gangguan kejiwaan seperti depresi, keputusasaan, dan keinginan bunuh diri. Permasalan kesehatan sosial anak jalanan yaitu masalah ekonomi dan sosial. Anak jalanan juga sering kali menjadi korban penelantaran, pelecehan psikologis, fisik, seksual dan rentan terkena penyakit infeksi seksual menular (HIV).

Sebuah tinjauan komprehensif menunjukkan bahwa anak jalanan mengalami tingkat keputusasaan, kerentanan terhadap gejala

\section{DAFTAR PUSTAKA}

Alem, H. W., \& Laha, A. (2019). Role of social intervention in addressing problems of street children: Evidences from the regional State of Oromia, Ethiopia. Indian Journal of Economics and Development, $7(5)$.

Arini, S., \& Pudjiati, S. R. R. (2017). The Correlation between Perceived Social Support and Mental Health among Adolescent Street Children. The Third Asia Future Conference.

Astri, H. (2018). Kehidupan anak jalanan di Indonesia: Faktor penyebab, tatanan hidup dan kerentanan berperilaku menyimpang. Aspirasi: Jurnal Masalah-Masalah Sosial, 5(2), 145-155.

Attia, M. S., Tayel, K. Y., Shata, Z. N., \& Othman, S. S. (2017). Psychosocial profile of institutionalised street children in Alexandria, Egypt: A comparative study with school children. Journal of Child \& Adolescent Mental Health, 29(2), 103-116. https://doi.org/10.2989/17280583.2017.13 39606

Ayub, T., Kumar, D., \& Shora, T. N. (2016). Psychosocial, demographic, educational and health characteristics of street children-a qualitative study. International Journal of Medical Science and Public Health, 5(08), 1.

Bhusal, S. (2016). Street Children in Butwal Municipality: A Case Study. Tribhuvan University Journal, 29(1), 191-202. depresi yang tinggi. Karena anak jalanan tidak memiliki kemampuan untuk mendapatkan pekerjaan yang layak, mereka menghadapi penindasan, penyiksaan, rasa tidak aman dan masalah lainnya saat hidup di jalanan.

Hal ini berdampak buruk pada perkembangan anak jalanan dan seringkali memiliki konsekuensi psikososial yang serius, seperti ketidakpercayaan pada anak, kurangnya kepercayaan diri dan hubungan interpersonal yang negatif. Karena kemudaan mereka, dan khususnya kurangnya kekuatan sosial, anak-anak dan remaja termasuk di antara yang paling parah terkena dampak dari keadaan yang merugikan tersebut. Permasalahan anak jalanan menjadi tanggung jawab bersama, Perlunya peran kerja sama lintas sektor baik pemerintah, masyarakat, dan institusi pendidikan untuk menyelesaikan permasalahan anak jalanan.

Cénat, J. M., Derivois, D., Hébert, M., Amédée, L. M., \& Karray, A. (2018). Multiple traumas and resilience among street children in Haiti: Psychopathology of survival. Child Abuse \& Neglect, 79, 85-97. https://doi.org/10.1016/j.chiabu.2018.01.024

Cumber, S. N., \& Tsoka-Gwegweni, J. M. (2015). The Health Profile of Street Children in Africa: A Literature Review. Journal of Public Health in Africa, 6(2), 566. https://doi.org/10.4081/jphia.2015.566

Deb, S., Sunny, A. M., \& Majumdar, B. (2020). Street Children: The Paradox of Untapped Human Resources. In Disadvantaged Children in India (pp. 1-47). Springer, Singapore.

Diallo, O., Wang, G., \& Toure, H. (2015). Livelihoods Used by Street Children for Survival in Bamako, Mali. International Journal of Psychological Studies, 8(1), p53.

Fiasorgbor, D. A., \& Fiasorgbor, E. K. (2015). Street children: Our health and coping strategies when we are sick. Journal of Health, Medicine and Nursing, 15(1), 45-50.

Hanafi, B. (2017). Keterlibatan Anak dalam Ekonomi Keluarga dan Pemenuhan HakHak Anak (Studi Kasus Anak Jalanan yang Bekerja di Terminal Terpadu Amplas Kelurahan Timbang Deli Kecamatan Medan Amplas). [Skripsi]. Medan: Fakultas Ilmu Sosial dan Ilmu Politik, Universitas Sumatera Utara. 
Haydar, S. (2017). Literacy Drive and Rehabilitation of the street children of Kolkata: An analytical study. Lulu. com.

Mugianti, S., Winarni, S., \& Pangestuti, W. D. (2018). Faktor Penyebab Remaja Menjadi Anak Jalanan. Jurnal Pendidikan Kesehatan (e-Journal), 7(1), 25-31.

Nayak, A. (2018). Health status of street children in Bhubaneswar, capital city of Odisha-A study. International Journal of Home Science, 4(2), 32-34.

Nuzula, F. (2019). Pengaruh Penyuluhan Tentang Personal Hygiene Dan Dampak Penyakit Yang Ditimbulkan Terhadap Tingkat Pengetahuan Pada Anak Jalanan (Studi pada Jaringan Kemanusiaan Jawa Timur di Malang). [Skripsi]. Malang: Universitas Muhammadiyah Malang.

Oppong Asante, K. (2016). Street Children and Adolescents in Ghana: A Qualitative Study of Trajectory and Behavioural Experiences of Homelessness. Global Social Welfare, $3(1), 33-43$. https://doi.org/10.1007/s40609-015-0039-8

Rakhmaniyah, A. (2020). Gambaran Kualitas Hidup Anak Jalanan yang Mengamen. [Skripsi]. Jakarta: Universitas Tarumanagara.

RamBihariLal Shrivastava, S. (2014). Developing a Coordinated Response to Counter the Public Health Menace of Street Children. Biology and Medicine, 06(03). https://doi.org/10.4172/0974$8369.1000 \mathrm{e} 112$

Ramu, K. (2018). A Descriptive Study to Assess the Selected Psychosocial Problems Among Street Children in Foster Homes at Tumkur, Karnataka, India. J Nurs Health Stud, 3(3), 10.
Suryaningsih, C., \& Nur, M. F. (2020). Pengalaman Hidup Anak Jalanan Usia Remaja. Jurnal Keperawatan Silampari, 4(1), 31-39.

Tefera, B. (2015). The situation of street children in selected cities of South Sudan: Magnitude, causes, and effects. Eastern Africa Social Science Research Review, 31(1), 63-87.

Tumangger, B. K., \& Riasih, T. (2020). Eksploitasi Terhadap Anak Jalanan Di Kota Bandung. Jurnal Ilmiah Perlindungan \& Pemberdayaan Sosial, 2(2).

UNICEF. (2019). UNICEF's mission statement. UNICEF's Mission Statement. https://www.unicef.org/about/who/index mission.html

Van Daalen, E., Hanson, K., \& Nieuwenhuys, O. (2016). Children's rights as living rights: The case of street children and a new law in Yogyakarta, Indonesia. The International Journal of Children's Rights, 24(4), 803-825.

Wardani, I. Y. (2018). Stres dan Strategi Koping Anak Jalanan di Kota Depok. Jurnal Persatuan Perawat Nasional Indonesia (JPPNI), 2(2), 108-116.

Zaman, B. (2019). Pendidikan Akhlak pada Anak Jalanan di Surakarta. INSPIRASI: Jurnal Kajian dan Penelitian Pendidikan Islam, 2(1), 129-146.

Zulfendri, Lubis, A., Salmah, U., \& Syahri, I. (2017). Health Problems of Street Children in the Medan Amplas Station. 2nd International Conference on Social and Political Development (ICOSOP 2017). 